\title{
Outcomes of Adjuvant Intravesical Mitomycin-C Treatment in Non-Muscle Invaziv High-Grade Bladder Cancer: Singe center experience
}

\section{Kas Invazyonu Yapmamış Yüksek Dereceli Mesane Kanserinde Adjuvan Intravezikal Mitomisin-C Uygulaması: Tek Merkez Deneyimi}

\author{
Özer Ural Çakıcı ${ }^{1}$, Nurullah Hamidi ${ }^{2}$ \\ ${ }^{1}$ Yıldırım Beyazıt Üniversitesi, Yenimahalle Eğitim ve Araştırma Hastanesi, Üroloji Kliniği, Ankara \\ ${ }^{2}$ Yıldırım Beyazıt Üniversitesi, Atatürk Eğitim ve Araştırma Hastanesi, Üroloji Kliniği, Ankara
}

\section{ÖZET}

GİRIŞ ve AMAÇ: Kas invazyonu yapmamış yüksek dereceli mesane kanserlerinin tedavisinde adjuvan intravesikal mitomisin-c tedavisinin sonuçlarını bildirmek

YÖNTEM ve GEREÇLER: Kliniğimizde Ocak 2012 ile Aralık 2018 tarihleri arasında mesane kanseri nedeniyle endoskopik tedavi uygulanmış hastaların patolojileri geriye dönük olarak değerlendirildi. Kas invazyonu yapmamış ve yüksek dereceli ürotelyal tümörü olan hastaların hastane başvuru kayıtları incelenerek adjuvan intravezikal mitomisin-c tedavisi almış olan hastaların bilgileri çalışmaya dahil edildi. Hastaların demografik verileri, sistoskopi bulguları, patolojik bulgular ve poliklinik başvuru kayıtları incelenerek analize dahil edildi.

BULGULAR: Toplam 54 hasta istatistiksel analize dahil edildi. Bu hastalar içinde 50 hastada patolojik evre T1 saptanırken 4 hastada patolojik evre Ta saptandı. Hiçbir hastada karsinoma in situ varlığı tespit edilmedi. Ortalama tümör boyutu $1.4 \mathrm{~cm}$ olarak bulundu. Adjuvan tedavi başlanması için endoskopik tedavi sonrasındaki bekleme süresi ortalama 2 (1-4) haftaydı. Ortalama takip süresi 21 ay olarak saptandı. Takiplerde evre ilerlemesi hastaların 14'ünde (\%26) görülürken yüksek dereceli nüks 22 hastada (\%41), düşük dereceli nüks 4 hastada (\%7) görüldü. Nüks görülen 22 hastanın 6'sında aynı zamanda ilerleme de görüldü.

TARTIŞMA ve SONUÇ: Kas invazyonu yapmamış yüksek dereceli mesane kanseri daha ileri evreye ilerleme ve nüks ihtimali yüksek bir kanser türüdür. Kılavuzlarda ilk önerilen adjuvan tedavi seçeneği intravezikal Bacillus-Calmette-Guérin suşu uygulamasıdır. Bizim sonuçlarımıza göre mitomycin-c tedavisi de adjuvan intravezikal tedavi için başarılı bir alternatif olarak değerlendirilebilir.

Anahtar Kelimeler: İntravezikal uygulama, Kemoterapi, Mesane kanseri, Mitomycin-c

\begin{abstract}
INTRODUCTION: The aim of the present study is to evaluate and report the clinical efficiacy of adjuvant intravesical mitomycin-c in the treatment of non-muscle invaziv high-grade bladder cancer patients of a tertiary single health-care center.

MATERIAL and METHODS: Electronic records of the patients who had undergone endoscopic treatment of bladder tumors between Jan 2012 and Dec 2018 are retrospectively reviewed. Data of the patients who were diagnosed with non-invasive high-grade urothelial carcinoma are further evaluated if adjuvant intravesical mitomycin-c therapy had been initiated and included in the study. Patient demographics, cystoscopy findings, pathological findings, and outpatients record are included in the analysis.

RESULTS: Total of 54 patients included in this study. Among them 50 patients had pT1 disease while 4 patients had pTa disease. None of the patients in this cohort had carcinoma-in-situ. Mean tumor diameter was 1.4 $\mathrm{cm}$. Mean time from initial transurethral resection to the application of the adjuvant therapy was 2 weeks (1-4 weeks). Mean follow-up time was 21 months. During the follow-up, tumor progression was observed in 14 (26\%) patients, high-grade tumor recurrence was observed in $22(41 \%)$ patients, and low-grade tumor recurrence was observed in 4 (7\%) patients. Among the 22 patients who had high-grade recurrence, 6 patients had also tumor progression during the follow-up
\end{abstract}


DISCUSSION AND CONCLUSION: Non-invasive high-grade bladder cancer holds significant risk of stage progression and recurrence. The contemporary clinical guidelines endorse adjuvant intravesical BCG treatment in the management of non-muscle invasive bladder cancer. Due to our results, adjuvant intravesical mitomycin-c therapy can be considered as a accomplished alternative.

Keywords: Bladder cancer, Chemoterapi, Intravesical instillation, Mitomycin-c

\section{GíRIŞ}

Mesane kanseri güncel epidemiyolojik bulgulara göre tüm dünyada en sik görülen kanserler arasinda dokuzuncu siradır (1). Mesane kanseri gelişiminde genetik yatkınlığın yanısıra sigara ve diğer tütün ürünlerinin kullanımı, içme suyundan yüksek arsenik maruziyeti, aromatik aminlere maruziyet, erkek cinsiyet ve omurilik hasarı sonrası nörojenik mesane oluşumu da suçlanmıştır $(2,3)$.

En sik görülen mesane kanseri tipi ürotelyal karsinomlar olup mesane kanserinin prognozunun öngörülmesinde en önemli faktörler patolojik tümör evresi ve derecesidir (4). Yüksek dereceli ürotelyal karsinomlar nüks ve ilerleme yönünden önemli bir risk taşırlar. Kas invazyonu yapmış olan mesane ürotelyal karsinomlarına önerilen tedavi radikal sistektomi iken kas invazyonu yapmamış yüksek dereceli mesane ürotelyal karsinomları çoğunlukla tekrarlayan mesane tümörünün transüretral rezeksiyonu (TURMT) ve adjuvan intravezikal tedaviler ile tedavi edilebilmektedir (5). Güncel k1lavuzlarda yüksek dereceli mesane ürotelyal karsinomu için adjuvan intravezikal tedavide ilk seçenek hem rekürensi hemde evre ilerlemesini engellediği için Bacillus-CalmetteGuérin (BCG) suşu uygulamalarıdır. İntravezikal Mitomycin-C (MMC) kemoterapi uygulamas1 BCG'ye alternatif olarak bildirilmektedir (6).

$\mathrm{Bu}$ çalışmada biz kas invazyonu yapmamış olan yüksek dereceli mesane ürotelyal karsinomu hastalarında birinci basamak adjuvan tedavide intravezikal MMC kullanımı sonuçlarımızı bildirmeyi amaçladık.

\section{MATERYAL ve METOD}

Yerel etik kurul onayını (onay numaras1: 2018/56) takiben Ankara Yenimahalle Eğitim ve Araştırma Hastanesinde Üroloji Kliniğinde Ocak 2012 ile Aralık 2018 tarihleri arasında TUR-MT yapilan hastaların verileri geriye yönelik tarand1. TUR-MT sonucu edinilen spesmenlerinde yüksek dereceli ürotelyal karsinom saptanan hastaların takip ve poliklinik kayıtları incelenerek adjuvan tedavide intavezikal indüksiyon ve idame MMC uygulanan hastaların verileri analize alındı. Hastaların yaşları, sigara içme öyküleri, cinsiyetleri, başvuru şikayetleri, eş zamanlı hastalıkları ve ailevi kanser öyküleri gibi demografik veriler kaydedildi. Hastaların ilk tanı aldıkları patoloji sonuçları, takiplerindeki nüks ve ilerleme bilgileri klinik veriler olarak toplandi.

İndüksiyon dozu olarak 6 hafta boyunca haftada bir kez $40 \mathrm{mg}$ dozunda intravezikal olarak verildi. MMC verilirken ilacın mesane içinde etkin konsantrasyona ulaşabilmesi için hastanın sıvı alımı ve mesane irrigasyonu 2 saat süreyle kapatıld1. İdame doz olarak her 3 ayda bir 3 hafta boyunca haftada bir kez $40 \mathrm{mg}$ dozunda MMC verildi. MMC verilirken hastanın mesane perforasyonu ve aktif hematüri olmamasına dikkat edildi.

\section{BULGULAR}

Hasta grubumuzun ortalama yaş ve ortalama tümör boyutu sirasiyla 71 (58-76) ve 1.4 (0.54.2) $\mathrm{cm}$ olarak saptandı. Çalışmamızdaki 50 hastaya yüksek dereceli, lamina propria invazyonu yapmış (T1Ghigh) fakat derin kas dokusu invazyonu yapmamış yüksek dereceli ürotelyal karsinom tanısı ile 4 hastaya ise lamina propria invazyonu yapmamış (TaGhigh) yüksek dereceli ürotelyal karsinom tanısı ile adjuvan intravezikal MMC tedavisi verilmişti. TUR-MT ile adjuvan intravezikal tedavi arasında geçen süre ortalama 2 (1-4 hafta) hafta olarak saptandi. Ortalama takip süremiz 21 (12-48 ay) ay olarak bulundu. Takiplerde evre ilerlemesi (progresyon) hastaların 14'ünde (\%26) görülürken yüksek dereceli rekürens 22 hastada $(\% 41)$, düşük dereceli rekürens 4 hastada (\%7) görüldü. Nüks görülen 22 hastanın 12'sinde aynı zamanda ilerleme de görüldü. Çalışmamızdaki 
hasta grubunun demografik ve klinik verileri sırası ile Tablo 1'de gösterilmiştir.

\section{TARTIŞMA}

Mesane kanseri günümüzde önemli bir toplum tabanlı sağlık sorunu konumundadır [7]. Mesane kanseri tedavisinde temel belirleyici unsur tümörün patolojik derecesi ve evresi olup yüksek dereceli tipler ile düşük dereceli patolojik tiplerin klinik seyirleri birbirleriyle büyük farklar göstermektedir. Kas invazyonu yapmamış yüksek dereceli mesane kanserleri ciddi bir nüks ve ilerleme riski taşımaktadır ve bu nedenle adjuvan tedaviler hastalığın izleminde vedaha ileri evrelere progresyonu engellemede önem kazanmıştır [8]. Bu evre ve derecedeki mesane ürotelyal karsinomlarında adjuvan tedavinin temelini mesane içine uygulanan BCG suşları veya kemoterapotik ajanlar oluşturmaktadır. Özellikle son dönemde görülen BCG suşları üretimindeki kesintiler sırasında ve sonrasında intravezikal kemoterapotik uygulamaları önemli bir tedavi alternatifi veya esas tedavi protokolü olarak değerlendirilmişlerdir. $[9,10]$.

Tablo 1. Hastaların demografik özellikleri

\begin{tabular}{|l|l|}
\hline Parametreler & $\mathrm{n}=54$ \\
\hline Yaş, Ortalama \pm SD & $71 \pm 4(58-76)$ \\
\hline Cinsiyet(Kadın), n (\%) & $14(26)$ \\
\hline $\begin{array}{l}\text { Tümör boyutu, Ortalama } \pm \text { SD } \\
\text { Min-maks) }\end{array}$ & $1.4 \pm 0.7(0.5-4.2)$ \\
İlk rezeksiyon sırasında & \\
patolojik T evresi, $\mathrm{n}(\%)$ & $4(7.4)$ \\
Ta & $50(92.6)$ \\
(Min-maks) & \\
\hline $\begin{array}{l}\text { Takip süresi (Ay), } \\
\text { Ortalama } \pm \text { SD }\end{array}$ & \\
\hline
\end{tabular}

\begin{tabular}{|l|l|}
\hline Takiplerde progresyon, $\mathrm{n}(\%)$ & $14(26)$ \\
\hline Takiplerde rekürens, $\mathrm{n}(\%)$ & $26(48)$ \\
\hline
\end{tabular}

Literatürdeki yayınlar incelendiğinde, bizim hasta grubumuzdan farklı olarak, bir çok çalışmada intravezikal MMC uygulamasının radyoterapi ile birlikte, BCG idamesi yerine, sistemik kemoterapi ile birlikte, ilk TUR-MT sonrasinda tek dozluk adjuvan intravezikal terapi amaciyla veya nispeten yeni bir tedavi alternatifi olan kemo-hipertermi protokollerinde kullanıldığg görülmektedir [1114]. Bizim çalışmamızda ise intravezikal MMC uygulaması yüksek dereceli kas invazyonu yapmamış ürotelyal karsinom olgularında birincil adjuvan tedavi olarak kullanılmıştır. Her ne kadar güncel klinik rehberlerde intravezikal MMC tedavisi öneriliyor olsa da birçok merkezde öncelikli klinik kullanımda olmadığı bildirilmiştir [15]. Son dönemde görülen BCG suşları üretimindeki azalma MMC kullanımında gözle görülür bir artışa neden olmuştur $[9,10]$. Kliniğimizde ise düşük yan etki profili, hızlı ve düzenli elde edilebilmesi ve uygulama kolaylıkları nedeni ile özellikle tek bir lezyonu olan ve lezyon boyutu $3 \mathrm{~cm}$.'den küçük olan kas invazyonu yapmamış yüksek dereceli ürotelyal karsinomlarda intravezikal adjuvan tedavide MMC öncelikle tercih edilmiştir. Bu yaklaşım ile literatürde sonuçları mevcut birçok kurumdan ayrılmaktayız.

İntravezikal kemoterapi uygulamasının kanser nüksünü önlerken evre ilerlemesi üzerinde etkili olmadığ Toplamda 9 farklı randomize kontrollü çalışmanın ve 2820 hastanın bireysel verilerinin incelendiği bir meta-analiz çalışmasında uzun dönem kansere özgün veya genel sağkalım yönünden intravezikal BCG ile MMC uygulamaları arasında fark bulunmamıştır. Fakat kanser rekürensinin önlenmesinde BCG başlangıç ve idame protokolünün daha üstün olduğu sonucuna varılmıştır [16]. Farklı bir meta-analizde yine sağkalım üzerine fark bildirilmemiş olup BCG ile kombine MMC tedavisinin ilerleme ve nüksleri önlemede hem yalnız BCG hem de MMC tedavilerine üstün olduğu bildirilmiştir [17]. Genel ve kansere özgün sağ kalım üzerine etkisinin olmaması, güncel klinik

Adress for correspondence: Özer Ural Çakıcı, Yenimahalle Eğitim ve Araştırma Hastanesi, Üroloji Kliniği, Ankara - Türkiye

e-mail: ozerural@hotmail.com

Available at www.actaoncologicaturcica.com

Copyright $\odot$ Ankara Onkoloji Hastanesi 
rehberlerde ve çalışmalarda öncelikle bir tedavi seçeneği olarak bildirilmiş olması nedeniyle klinik uygulamamız olan öncelikli intravezikal MMC uygulamasının klinik ve etik yönlerden uygun olduğu düşüncesindeyiz.

Järvinen ve arkadaşları 68 mesane carcinoma-in-situ hastasını içeren hasta gruplarında MMC ile BCG + MMC kollarını karşılaştırmışlar[18]. Bu çalışmanın sonucuna göre MMC kolunda nüks oranı $\% 54$ ve ilerleme oranı $\% 40$ olarak bildirilmiştir [18]. Bizim çalışmamızda carcinoma-in-situ olan hasta bulunmamaktayd. Järvinen ve arkadaşlarının bildirdiği nispeten yüksek nüks oranları carcinoma-in-situ vakalarında görülen yüksek nüks ve ilerleme yatkınlığına bağlanabilir. Addeo ve arkadaşları ise bir faz 3 çalışmasında gemsitabin ile MMC'i karşılaştırarak MMC kolunda \%36.6 nüks oranı ve \%16.6 ilerleme oranı bildirmişlerdir [19]. Addeo ve arkadaşlarının sonuçları ile bizim sonuçlarımız birbiri ile benzerdir. Ojea ve arkadaşları tarafindan yapılan ve farklı BCG dozlar1 ile tam doz MMC tedavisinin sonuçlarını karşılaştıran randomize bir çalışmanın sonuçlarında da MMC kolu için nüks oranı $\% 40$ olarak bildirilmiştir [20]. Lamm ve arkadaşlarının çalışmasında ise MMC ve BCG kolları karşılaştırılmış, sonuç olarak sağ kalım yönünden her iki kol eşit bulunmuştur. Bu çalışmada ise MMC kolu için nüks oran $1 \% 54$, ilerleme oran 1 ise $\% 13$ olarak bildirilmiştir [21]. Öncesinde bildirilen vaka serileri ile karşılaştırıldığında nüks oranlarımızın kabul edilebilir seviyelerde ve önceki bildirilen oranlarla uyumlu olduğu görülmektedir. Bizim hasta grubumuzda nüks oranı \%36 (25 hastadan 9'u), evre ilerleme oranı ise \%16 (25 hastadan 4'ü) olarak saptanmıştır. Bizim sonuçlarımızın tümör boyutu küçük hastaların çalışma grubunda olmas1 ve carcinoma-in-situ tanılı hasta bulunmaması nedeniyle önceki çalışmalardan nispeten daha iyi olduğu da düşünülebilir.

Çalışmamızın retsopektif oluşu, takip süresinin kısa oluşu ve düşük hasta sayısına sahip olması başlıca kısıtlayıcı faktörlerdir. Ayrıca çalışmaya dahil edilen hastaların mesane tümörüne eşlik eden carcinoma-in-situ olmaması çalışmamızın önceki çalışmalar ile karşılaştırılmasını güç hale getirmiştir.

\section{SONUC}

Mevcut kanıtlar ışığında iyi seçilmiş vakalarda kas invazyonu yapmamış yüksek dereceli mesane kanseri vakalarında intravezikal MMC tedavisi kabul edilebilir sonuçları ve düşük yan etki profili olan bir tedavi yöntemi olarak ilk basamak tedavide veya BCG tedavisi başlanmış hastalarda idame tedavide seçilebilecek bir alternatiftir. Ancak sonuçlarımızın daha iyi desteklenebilmesi için daha yüksek hasta sayılı ve prospektif çalışmalara ihtiyaç bulunmaktadır.

\section{REFERANSLAR}

1. Antoni S, Ferlay J, Soerjomataram I, Znaor A, Jemal A, Bray F. Bladder Cancer Incidence and Mortality: A Global Overview and Recent Trends. Eur Urol. 2017 Jan;71(1):96-108.

2. Letašiová $S$, Medve'ová $A$, Šovčíková $A$, Dušinská M, Volkovová K, Mosoiu C, Bartonová A. Bladder cancer, a review of the environmental risk factors. Environ Health. 2012 Jun 28;11 Suppl 1:S11.

3. Böthig R, Kurze I, Fiebag K, Kaufmann A, Schöps W, Kadhum T, Zellner M, Golka K. Clinical characteristics of bladder cancer in patients with spinal cord injury: the experience from a single centre. Int Urol Nephrol. 2017 Jun;49(6):983-994.

4. Bladder cancer: diagnosis and management of bladder cancer: (C) NICE (2015) Bladder cancer: diagnosis and management of bladder cancer. BJU Int. 2017 Dec;120(6):755-765.

5. Alfred Witjes J, Lebret $\mathrm{T}$, Compérat EM, Cowan NC, De Santis M, Bruins HM, Hernández V, Espinós EL, Dunn J, Rouanne M, Neuzillet Y, Veskimäe E, van der Heijden AG, Gakis G, Ribal MJ. Updated 2016 EAU Guidelines on Muscleinvasive and Metastatic Bladder Cancer. Eur Urol. 2017 Mar;71(3):462-475.

6. Zargar $\mathrm{H}$, Aning $J$, Ischia $J$, So A, Black $P$. Optimizing intravesical mitomycin $\mathrm{C}$ therapy in non-muscle-invasive bladder cancer. Nat Rev Urol. 2014 Apr;11(4):220-30.

7. Leal J, Luengo-Fernandez R, Sullivan R, Witjes JA. Economic Burden of Bladder Cancer Across the European Union. Eur Urol. 2016 Mar;69(3):438-47.

8. Reisz PA, Laviana AA, Chang SS. Management of High-grade T1 Urothelial Carcinoma. Curr Urol Rep. 2018 Oct 26;19(12):103.

9. Messing EM. The BCG Shortage. Bladder Cancer. 2017 Jul 27;3(3):227-228.

10. Brausi M, Morselli S. The treatment of Ta-T1 bladder cancer in the era of worldwide BCG shortage. Minerva Urol Nefrol. 2016 Apr;68(2):1923.

11. Deng T, Liu B, Duan X, Zhang T, Cai C, Zeng G. Systematic Review and Cumulative Analysis of the Combination of Mitomycin $\mathrm{C}$ plus Bacillus Calmette-Guérin (BCG) for Non-Muscle-Invasive Bladder Cancer. Sci Rep. 2017 Jun 9;7(1):3172.

12. Xylinas E, Kent M, Dabi Y, Rieken M, Kluth LA,

Adress for correspondence: Özer Ural Çakıcı, Yenimahalle Eğitim ve Araştırma Hastanesi, Üroloji Kliniği, Ankara - Türkiye

e-mail: ozerural@hotmail.com

Available at www.actaoncologicaturcica.com

Copyright $\odot$ Ankara Onkoloji Hastanesi 
Al Hussein Al Awamlh B, Ouzaid I, Pycha A, Comploj E, Svatek RS, Lotan Y, Karakiewicz PI, Holmang S, Shariat SF. Impact of age on outcomes of patients with non-muscle-invasive bladder cancer treated with immediate postoperative instillation of mitomycin C. Urol Oncol. 2018 Mar;36(3):89.e189.e5.

13. León-Mata J, Domínguez JL, Redorta JP, Sousa González D, Alvarez Casal M, Sousa Escandón A, Piñeiro Vázquez E. Analysis of tolerance and security of chemo hyperthermia with Mitomycin C for the treatment of non-muscle invasive bladder cancer. Arch Esp Urol. 2018 May;71(4):426-437.

14. Bosschieter $J$, Nieuwenhuijzen JA, Vis AN, van Ginkel T, Lissenberg-Witte BI, Beckers GMA, van Moorselaar RJA. An immediate, single intravesical instillation of mitomycin $\mathrm{C}$ is of benefit in patients with non-muscle-invasive bladder cancer irrespective of prognostic risk groups. Urol Oncol. 2018 Sep;36(9):400.e7-400.e14.

15. Reis LO, Moro JC, Ribeiro LF, Voris BR, Sadi MV. Are we following the guidelines on non-muscle invasive bladder cancer? Int Braz J Urol. 2016 JanFeb;42(1):22-8.

16. Malmström PU, Sylvester RJ, Crawford DE, Friedrich M, Krege S, Rintala E, Solsona E, Di Stasi SM, Witjes JA. An individual patient data metaanalysis of the long-term outcome of randomised studies comparing intravesical mitomycin $\mathrm{C}$ versus bacillus Calmette-Guérin for non-muscle-invasive bladder cancer. Eur Urol. 2009 Aug;56(2):247-56.

17. Lan $Y$, Liu D, Lin $M$. Comparison of the combination therapy of bacillus Calmette-Guérin and mitomycin $\mathrm{C}$ with the monotherapy for nonmuscle-invasive bladder cancer: a meta-analysis. Neoplasma. 2016;63(6):967-976.
18. Järvinen $\mathrm{R}$, Kaasinen E, Rintala E. Long-term results of maintenance treatment of mitomycin $\mathrm{C}$ or alternating mitomycin $\mathrm{C}$ and bacillus CalmetteGuérin instillation therapy of patients with carcinoma in situ of the bladder: A subgroup analysis of the prospective FinnBladder 2 study with a 17-year follow-up. Scand J Urol Nephrol. 2012; 46:411-417.

19. Addeo R, Caraglia M, Bellini S, Abbruzzese A, Vincenzi B, Montella L, Miragliuolo A, Guarrasi R, Lanna M, Cennamo G, Faiola V, Del Prete S. Randomized phase III trial on gemcitabine versus mytomicin in recurrent superficial bladder cancer: evaluation of efficacy and tolerance. J Clin Oncol. 2010 Feb 1;28(4):543-8. doi: 10.1200/JCO.2008.20.8199.

20. Ojea A, Nogueira JL, Solsona E, Flores N, Gómez JM, Molina JR, Chantada V, Camacho JE, Piñeiro LM, Rodríguez RH, Isorna S, Blas M, MartínezPiñeiro JA, Madero R; CUETO Group (Club Urológico Español De Tratamiento Oncológico). A multicentre, randomised prospective trial comparing three intravesical adjuvant therapies for intermediate-risk superficial bladder cancer: lowdose bacillus Calmette-Guerin (27 mg) versus very low-dose bacillus Calmette-Guerin $(13.5 \mathrm{mg})$ versus mitomycin C. Eur Urol. 2007 Nov;52(5):1398-406.

21. Lamm DL, Blumenstein BA, David Crawford E, Crissman JD, Lowe BA, Smith JA Jr, Sarosdy MF, Schellhammer PF, Sagalowsky AI, Messing EM, Loehrer P, Barton Grossman H. Randomized intergroup comparison of bacillus calmette-guerin immunotherapy and mitomycin C chemotherapy prophylaxis in superficial transitional cell carcinoma of the bladder a southwest oncology group study. Urol Oncol. 1995 May-Jun;1(3):119-26. 